\title{
Research on the Three Stages of Fiscal and Tax Policies Corresponding to Technological Innovation of Enterprises
}

\author{
Junhui Yin ${ }^{a}$, Xue Bai ${ }^{b}$ \\ Tianjin University of Science\& Technology, Tianjin 300222, China. \\ a junhuiyin@126.com, bbaixue1905@163.com
}

Keywords: Fiscal policy; Technological innovation; Three phases.

\begin{abstract}
The innovation-driven development strategy is now firmly rooted in people's minds. As an important carrier of innovation, enterprises need to improve their economic benefits through technological innovation. By looking up the data and comparing the fiscal policies implemented by the developed countries such as the United States and Japan, the characteristics of the three stages of technological innovation and the required policy support, founded that China's current fiscal and taxation policies have deficiencies, and then proposed fiscal and taxation policies that are suitable for the development of the period so as to ensure that enterprises can better promote technological innovation.
\end{abstract}

\section{Introduction}

Profitability is the ultimate goal of the company's production and operation activities. Only through continuous technological innovation can the company achieve continuous economic growth. At the same time, corporate innovation lays the foundation for the construction of an innovative country and is an important part of the innovation-driven development strategy[1]. However, the uncertainty and complexity of technological innovation has led most companies to adopt replication models rather than innovation models. Fiscal and taxation policies are used as tools to make up for market failures and to adjust the income gap, and they play a role in promoting companies to carry out technological innovations[2]. Technological innovation includes the R\&D phase, the outcome transformation phase, and the industrialized production phase. These three phases require different policies to support them. These tax policies are divided into three kinds of financial investment, tax incentives and government procurement.

\section{The Effect of Fiscal and Tax Policies on Technological Innovation of Enterprises}

\subsection{The Role of Fiscal Policy in The Research and Development Stage}

The R\&D phase is the first step for companies to start investing resources in researching and developing new technologies and transforming innovative thinking into practice. In this link, companies will develop new products and invest in new markets to meet people's new needs. First of all, the R\&D phase requires a large amount of capital investment. The development of new technologies, new products, and new markets requires the input of a large number of scientific research personnel and experimental equipment. The capture of scientific research problems requires a lot of funds as support. Second, there is instability in the R\&D phase, and not all inputs can get corresponding output. Any problem at any stage of the experiment may lead to stagnation of research and development, or even a failure.

Judging from the characteristics of the R\&D stage, fiscal and taxation policies at this stage should focus on fiscal input and tax incentives. Financial investment has injected a large amount of stable funds for enterprises in the R\&D stage, strengthened the company's capital supply chain, and provided solid financial support for the scientific research process; the gratuitous and targeted nature of financial input can guide enterprises to carry out technological innovation and make related companies obtain rapid growth. The tax benefits greatly reduce the cost of corporate research, such as the current allowable companies to deduct the technical development costs actually incurred in the 
year to increase corporate profits, reduce the risk of corporate research and development, but also increase the company to carry out technological innovation enthusiasm.

\subsection{The Role of Fiscal and Tax Policies in the Transformation of Achievements}

The transformation of results is the stage when companies transfer the results of innovation from the scientific research department to the production department for commercialization. This stage is to undertake the scientific research results of the previous stage, and lay the foundation for the next phase of industrial production, and determine whether the innovation results have use value.

This phase is similar to the characteristics of the R\&D phase. It still requires a large amount of capital injection and the results are also uncertain. First of all, the commercialization of scientific research results may not be able to meet the expectations of research and development, or the results of scientific research cannot be commercialized at all. Although there is value, there is no corresponding use value. Secondly, the production equipment and production personnel required for commercialization still require companies to inject large amounts of funds as support. At this stage, financial input and tax incentives can reduce the capital pressure on companies, reduce conversion costs, and promote the successful transformation of technological innovation achievements.

\subsection{The Role of Fiscal Policy in Industrial Production}

The industrialized production stage is the final step of technological innovation. At this stage, the company will mass-produce the commercialization of innovation and put it into the market. Largescale production at this stage requires the purchase of a large number of professional equipment, recruitment of production personnel, and training of personnel. At this stage, the scale of capital investment even exceeds the previous two stages. The market prospect of technology is still uncertain. If new products are difficult to occupy the market share and are favored by consumers, the technological innovation of the company will still fail.

At this stage, we should focus on tax incentives and fiscal policies for government procurement. Tax benefits reduce the company's production costs and corporate production risks. And government procurement is a direct driving force for increasing the enthusiasm of enterprises. Government procurement can directly and effectively expand the market scale, reduce the uncertainty of technological innovation, promote the combination of technological innovation and market economy, and also promote development of relevant high-tech enterprise.

\section{Insufficiency of Current Fiscal Policy}

In recent years, China has continuously improved its fiscal and taxation policies, formulated scientific and reasonable policies, vigorously promoted technological innovation activities of enterprises, and improved previous one-sided problems, but there are still some gaps compared with other countries. The country is now implementing an innovation-driven development strategy. At this time, it is the stage in which high-tech technological innovation is developing at a high speed. Therefore, it is also necessary to reform fiscal and taxation policies as soon as possible to suit their development, and to make use of fiscal and taxation policies to promote the role of technological innovation in enterprises.

\subsection{Inadequate Fiscal and Taxation Policies in the R\&D Phase}

Table 1. Total financial expenditures for scientific research (2012-2016)

\begin{tabular}{cccccc}
\hline & 2012 & 2013 & 2014 & 2015 & 2016 \\
\hline Percentage of total financial expenditure $(\%)$ & 1.76 & 1.78 & 1.74 & 1.71 & 1.67 \\
Percentage of GDP(\%) & 0.41 & 0.42 & 0.41 & 0.44 & 0.42 \\
\hline
\end{tabular}

First, the national financial science and technology allocations are small. From Table 1, it can be seen that China's financial science and technology allocations accounted for a slight decrease in the total financial expenditure after 2013 , accounting for $0.42 \%$ of the GDP, with the highest percentage being $0.44 \%$ in 2015 . This figure is far lower than the ratio of financial science and technology input of developed countries to GDP, which is mostly above 3\% in developed countries. In Japan, the government takes direct financial investment in the technological innovation of enterprises, and it 
also provides low-interest or interest-free loans to enterprises, enabling them to have sufficient funds for technological innovation.

The second is to promote the development of new technology research and development companies tax incentives in a single form. China's tax incentives for enterprises are mainly concentrated on corporate income tax, and most of the preferential tax policies enjoyed by small and medium-sized enterprises are that after the company obtains high-tech enterprise recognition, corporate income tax uses a low tax rate of $15 \%$. This highly-targeted "preferential" policy has a small scope of influence and has little effect on corporate technological innovation. Whereas the U.S. government stipulates that corporate $\mathrm{R} \& \mathrm{D}$ expenses exceed the average of the previous three years, more than $25 \%$ can directly deduct income tax, the salaries of researchers engaged in scientific research are exempted from personal income tax, and the tax rates of venture capital are reduced. These diverse policies have a wide range of influence, not only injecting large amounts of social funds into enterprises, but also increasing people's enthusiasm for scientific research[3].

\subsection{Insufficient Financial and Taxation Policies at the Stage of Achievement Transformation}

China's fiscal investment focuses on the R\&D phase, and tax incentives focus on the stage of profit-making after the completion of the transformation of achievements. This means that the resultstransformation phase has not received corresponding attention no matter whether it is invested in fiscal funds or in tax policies. In China, enterprises and public institutions are temporarily exempted from income tax with a net income of 300,000 yuan or less in the form of technology transfer and technical consultation, technical services, and technical training related to technology transfer during the process of technology transfer, these measures can only maintain the current level of technology transfer without playing an incentive role. U.S. Government's Small Business Innovation Research Program, which assists patent applicants and promotes the transformation of research results of small businesses. Australia charges the cost of the company's purchase of technological innovations into public welfare expenditures, exempts taxes and fees, and allows technological innovations to flow rapidly between R\&D institutions and enterprises. Comparing the financial and taxation policies of developed countries in the transformation of achievements, we can see that China's policies are seriously missing at this stage.

\subsection{Insufficient Financial and Taxation Policies in Industrial Production}

In the stage of industrialized production of technological innovations, developed countries also provided continuous support to companies in terms of tax incentives and government procurement. For example, in Japan, computer manufacturers purchased new equipment, built new factories, and were exempt from paying investment taxes. In 1964, Japan reduced the depreciation period of machinery equipment for the entire industry by $55 \%$. In terms of government procurement, Japan's innovative procurement methods, for public technology procurement, the government can sign orders with new technology that the company does not have at the time and can generate new technology within a reasonable period of time. U.S. policy formulation in government procurement is also particularly stringent. U.S. legislation provides that federal governments must purchase products and services from domestic companies when they maintain the products and services they need to purchase. Moreover, there are certain policy inclinations for the purchase of the latest technology products of the company, which can be used to purchase high-tech products that are unmarketable by the company at prices higher than the market price. The guiding role played by these policies has stimulated the market demand for innovative technology products and reduced the risk of technological innovation in the industrial production stage.

At this stage, China's tax incentives are still not perfect compared to developed countries, and they still tend to reduce income taxes and customs duties. Secondly, government procurement support is relatively small. At present, China's "Government Procurement Law" only provides some principles of the content, the specific implementation details still need to be improved. The first is that the government's criteria for determining "national goods" are not clear, which has led to many times that government procurement does not really support the products and services provided by domestic enterprises. Second, the government has too few purchases of technological innovation products from 
enterprises. At present, China's government procurement is still focusing on saving funds and sourcing too few new technology products.

\section{Countermeasures and Suggestions}

\subsection{Research on Financial and Tax Policies in the Research and Development Stage}

First, increase financial investment. First of all, we can learn from the experience of the United States through legislation to ensure the maximum proportion of financial capital investment, and inject a capital flow for enterprises in need, so that the company's technological innovation activities can be guaranteed. Second, we must establish a corresponding financial science and technology funds supervision and management mechanism. This can effectively play the role of financial science and technology funds and improve the efficiency of the use of funds.

Second, increase the universality and diversity of tax incentives at this stage. The incentives for technological innovation are not only unique to specific industries in specific regions, but should be reflected in specific projects, so that whether or not companies are located in high-tech development zones, whether they are related industries, as long as technological innovations related to the project, enjoy tax benefits. In addition, in addition to setting low tax rates, it is also necessary to increase policies such as adding deductions and adding amortization to reduce the cost of technological innovation and reduce the risk of technology research and development. Preferential tax policies can also be reflected in the reduction of consumption tax, value-added tax, and personal income tax. For example, the salary of R\&D personnel can be exempted from personal income tax, instead of a single increase in income tax relief[4].

\subsection{The Countermeasures and Proposals of Fiscal and Tax Policies in the Transformation of Achievements}

First, give play to the role of financial funds in supporting the transformation of results .At this stage, continue to increase financial input, subsidize materials required for the transformation of results, or provide enterprises with interest-free or low-interest loans to ensure the success of technological innovations. In addition, attention should also be paid to the important position of technological innovation in SMEs. It is possible to directly provide SMEs with funding assistance such as technical consultations and increase the number of patents for effective inventions.

Second, increase tax incentives with incentives. The first is that the purchaser of technological innovations can be given a tax exemption or reduced concessions, and the cost of purchasing innovative technological achievements can be included in public welfare expenditures to reduce taxes. The second is to give tax concessions to the conversion costs of the results. These costs can be deducted or added to the amortization, in order to reduce the cost of transforming the enterprise's achievements and reduce the uncertainty of the transformation of results.

\subsection{The Countermeasures of the Fiscal and Tax Policy in the Industrialized Production Stage}

In terms of tax incentives, the tax rate for innovative technology products should be reduced first. Low tax rates can lower the price of products and help open up markets for innovative technology products. Secondly, low tax rates should be imposed on production equipment purchased by enterprises, lower production costs, and increase productivity.

The optimization of government procurement mechanism also plays a guiding role. First, the government should not only purchase products for inquiry or purchase, but must first purchase technological innovation products from domestic high-tech industries. This not only increases the sales volume of products, but also reduces the uncertainty of technological innovation products. The second is that for certain specific innovative technology products, the government may adopt certain policy inclinations when purchasing, and support some technological innovation products such as basic science, national economy and people's livelihood, and national security. Thirdly, in the process of procurement, we can carry out necessary publicity for technological innovation products, play a role in guiding consumption, lay the foundation for technological innovation products to open up markets, and prevent consumers from questioning emerging products because they do not understand them. 


\section{References}

[1]. Wu Zuguang, Wan Xinyue, A Pei. Review of taxation issues affecting corporate R\&D investment. Future and development, Vol. 42(2018) No. 04, p. 73-80.

[2]. Guan Yonghao, Yang Yi, Zhang Chuang. Research on Tax Preferential Policies to Promote Enterprise Innovation. Qinghai Social Sciences, (2016) No. 06, p. 98-103+118.

[3]. Wang Peipei. International Comparison of R\&D Tax Incentives and Policy Suggestions. Finance Monthly, (2016) No. 31, p. 120-123.

[4]. Sun Ying. Tax Incentives and Corporate Science and Technology Innovation- — A Study Based on Differences in Tax Types and Preferential Methods. Journal of Shanghai Economic Management Cadre College, (2016) No04, p. 28-38. 